Check for updates

Cite this: RSC Adv., 2018, 8, 9057

Received 16th October 2017

Accepted 17th February 2018

DOI: 10.1039/c7ra11383h

rsc.li/rsc-advances

\section{Cytidine-stabilized copper nanoclusters as a fluorescent probe for sensing of copper ions and hemin}

\author{
Yong Wang, (D) *a Tianxia Chen, ${ }^{\text {a }}$ Zhengtao Zhang ${ }^{a}$ and Yongnian Ni (iD *ab
}

\section{Introduction}

In past years, research on biologically important metal ions and metalloproteins has attracted much attention from scientists due to their crucial role in many biological processes. Copper is the third most abundant trace element in the growth and development of the human body, and plays an important role in different biological processes such as transport of molecular oxygen, activation and electronic signal conversion, and so on. ${ }^{\mathbf{1 , 2}}$ However, the long-term exposure to excessive amounts of copper can affect body equilibrium, thereby seriously harming the health of the body to cause disease, such as Alzheimer's disease, Menkes disease, Parkinson's disease, and so on., Therefore, the development of a facile approach to quantitatively detect copper ions $\left(\mathrm{Cu}^{2+}\right)$ is always desirable. On the other hand, hemin, namely iron(III) protoporphyrin IX chloride, is an important natural compound and plays an essential role in an intracellular regulator system using oxygen. ${ }^{5}$ It has been widely used in the field of pharmacy, environmental science, biological science, and food industry. ${ }^{6-8}$ However, reports regarding hemin detection as an analyte are relatively scarce. Therefore, it is of great importance to develop a rapid, relatively simple and inexpensive method for trace detection of this useful substance.

Up to date, many approaches for the detection of $\mathrm{Cu}^{2+}$ or hemin have been well established, such as atomic absorption

${ }^{a}$ College of Chemistry, Nanchang University, Nanchang, Jiangxi 330031, China. E-mail: ynni@ncu.edu.cn; wangyong@ncu.edu.cn; Fax: +86 791 83969500; Tel: +86 79183969500

${ }^{b}$ State Key Laboratory of Food Science and Technology, Nanchang University, Nanchang, Jiangxi 330047, China spectrometry (AAS), inductively coupled plasma-atomic emission spectroscopy (ICP-AES), capillary electrophoresis, electrochemistry, and so on. ${ }^{9-14}$ However, most of these methods still suffer from shortcomings including complex operation process, expensive instruments, or time-consuming pretreatment, which limit their uses for analysis of $\mathrm{Cu}^{2+}$ or hemin. Fluorescence spectroscopy is one of the most common techniques used for routine analysis. Hence, it is well suited for the detection of $\mathrm{Cu}^{2+}$ or hemin. However, $\mathrm{Cu}^{2+}$ or hemin does not possess natural intrinsic fluorescence, and thus they cannot be quantitatively detected by direct fluorimetric analysis. An alternative method is to apply a fluorescent probe for their indirect determination. ${ }^{\mathbf{1 5 - 2 3}}$

More recently, fluorescent noble metal nanoclusters (NMNCs) have been reported to have many advantages like good photobleaching, excellent biocompatibility, non-toxicity and so on. ${ }^{24-26}$ As a result, many researchers paid attention to the NMNCs, particularly gold nanoclusters (AuNCs) or silver nanoclusters (AgNCs), as a new fluorescent probe to construct various (bio)sensors for the detection of analyte of interest. ${ }^{27-30}$ Particularly, some literature reported the use of diverse capping agents, such as bovine serum albumin, ${ }^{31-34}$ DNA, ${ }^{35}$ polyethyleneimine, ${ }^{36}$ polymethacrylic acid sodium, ${ }^{37}$ citrate, ${ }^{38}$ dithiothreitol, ${ }^{39}$ and D-penicillamine ${ }^{40}$ to synthesize NMNCs for $\mathrm{Cu}^{2+}$ detection. However, at present, the application of fluorescent copper nanoclusters (CuNCs) in the field of (bio)sensing lay behind their counterparts (AuNCs or AgNCs). In this work, we exploited the synthesized water-soluble cytidine-stabilized copper nanoclusters as a fluorescent probe for the detection of $\mathrm{Cu}^{2+}$ and hemin, respectively. It was found that $\mathrm{Cu}^{2+}$ can react with ascorbic acid as the reductant in the presence of cytidine in 


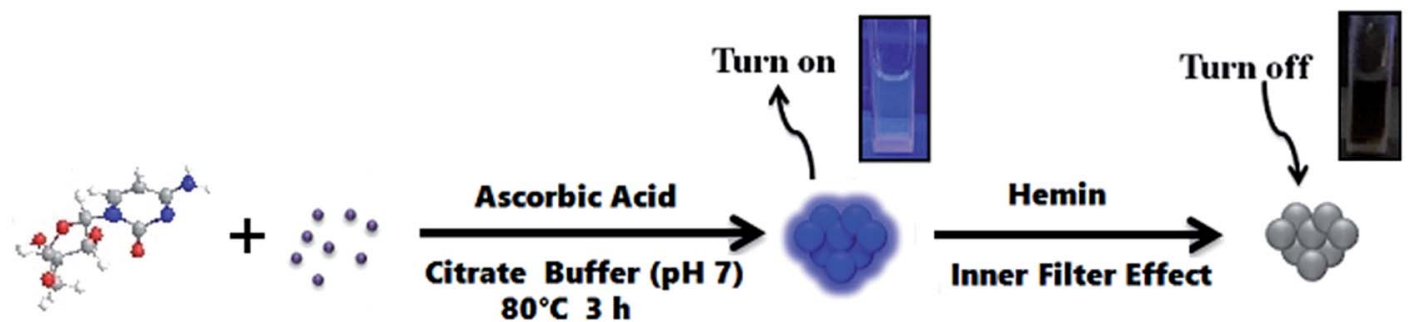

\section{Cytidine $\quad \mathrm{Cu}^{2+}$}

CuNCs

\section{Hemin-CuNCs}

Scheme 1 Schematic illustration of fluorescence "turn on-off" strategy for detection of $\mathrm{Cu}^{2+}$ and hemin.

the citrate buffer to form fluorescent CuNCs. Therefore, we made use of the formation reaction during the synthesis progress of the water-soluble fluorescent CuNCs to fabricate a selective $\mathrm{Cu}^{2+}$ "turn-on" sensor. In addition, we observed that the addition of hemin into fluorescent CuNCs could greatly diminish their fluorescence. Hence, the "turn off" process could be employed to develop a fluorescence quenching sensor for hemin detection. The sensing mechanism is briefly described in Scheme 1.

\section{Experimental}

\subsection{Reagents and chemicals}

Cupric nitrate trihydrate was bought from Tianjin Chemical Reagent 4th Factory Kaida Chemical Plant (Tianjin, China). Hemin were purchased from Sigma-Aldrich (USA). Cytidine and ascorbic acid and hydrochloric acid were purchased from Sinopharm Chemical Reagent Co., Ltd. (Shanghai, China). Citric acid and sodium hydroxide were bought from Xilong Chemical Reagent Co., Ltd. (Shantou, China). All of the chemical reagents are used as received with no further purification. Double distilled water was used in all experiments.

\subsection{Apparatus}

All fluorescence (FL) spectra were measured on a PerkinElmer LS-55 fluorescence spectrophotometer (PerkinElmer Co., USA) with a standard $10 \mathrm{~mm}$ path length quartz cuvette. UV-vis spectra were recorded with an Agilent 8453 UV-vis spectrometer (Agilent Technologies Co., USA) with a standard $10 \mathrm{~mm}$ path length quartz cuvette. Transmission electron microscopy (TEM) measurements were made using JEOL JEM-2100 transmission electron microscope (JEOL, Japan) operated at an accelerating voltage of $200 \mathrm{kV}$. X-ray photoelectron spectroscopy (XPS) characterization were conducted by using an ESCALab 220-Xi (VG, UK). Fourier transform infrared spectra (FT-IR) were collected in transmission mode by a Nicolet spectrometer equipped with a DTGS KBr detector and a $\mathrm{KBr}$ beam splitter.

\subsection{Fluorescent detection of $\mathrm{Cu}^{2+}$ and hemin}

In a typical experiment, the $\mathrm{Cu}^{2+}$ "turn-on" sensor was constructed on the basis of the formation of fluorescent CuNCs. Briefly, appropriate volumes $(x \mathrm{~mL})$ of $\mathrm{Cu}^{2+}$ standard solution, $0.12 \mathrm{~mL}$ of $10 \mathrm{mM}$ cytidine (final concentration: $1.2 \mathrm{mM}$ ) and selected volumes of $(0.59-x) \mathrm{mL}$ water were added directly into $1.5 \mathrm{~mL}$ plastic tube, and mixed thoroughly. After that, $0.15 \mathrm{~mL}$ of $20 \mathrm{mM}$ citrate buffer (final concentration: $3.0 \mathrm{mM}, \mathrm{pH}=7$ ) and $0.14 \mathrm{~mL}$ of $10 \mathrm{mM}$ ascorbic acid solution (final concentration: $1.4 \mathrm{mM}$ ) were successively added into the resulting mixture to give the final volume of $1.00 \mathrm{~mL}$. Then, the mixture solution was mixed well and maintained at $80{ }^{\circ} \mathrm{C}$ for 3 hours. After the solution was cooled to room temperature, bright blue fluorescence could be observed under a $365 \mathrm{~nm}$ UV light, denoting the formation of CuNCs. At the same time, fluorescence assays were operated. The emission spectra were collected with the excitation at $300 \mathrm{~nm}$.

For the detection of hemin, the CuNCs were firstly prepared as a "turn-off" fluorescent probe. During the synthesis of the fluorescent CuNCs, we selected $40 \mu \mathrm{M} \mathrm{Cu}^{2+}$ on the basis of the higher fluorescence intensity. Then, appropriate volumes of hemin standard solution were added into $0.06 \mathrm{~mL}$ of the asformed CuNCs solution, following by $1.94 \mathrm{~mL}$ of $\mathrm{H}_{2} \mathrm{O}$. Next, the as-prepared solution was mixed well. After 5 min incubation, the emission spectra were collected with the excitation at $300 \mathrm{~nm}$.

\subsection{Analysis of $\mathrm{Cu}^{2+}$ in lake water samples}

The water samples were collected from the Runxi Lake (Nanchang University, Jiangxi, China). The collected samples were filtered through a $0.22 \mu \mathrm{m}$ membrane and then centrifugated for $15 \mathrm{~min}$ at $10000 \mathrm{rpm}$ to remove possible impurities. A recovery test was conducted on the samples spiked with $\mathrm{Cu}^{2+}$ at three different concentrations $(1.0,1.5$ and $2.0 \mu \mathrm{M})$. The concentration of $\mathrm{Cu}^{2+}$ was analyzed by the above-proposed method.

\subsection{Analysis of hemin in duck blood samples}

All animal handling and experimental procedures were performed in accordance with the Guidelines of the First Affiliated Hospital of Nanchang University and were approved by the Ethics Committee of School of Life Sciences, Nanchang University.

The duck was fixed and the inner feathers of the duck wings were removed. After disinfecting the vein of wings, the blood collection device was inserted into the blood vessel, the blood was slowly returned to the needle syringe and the blood was collected. Then let the duck free after a local treatment. 
The fresh duck blood samples were washed with $\mathrm{NaCl}$ injection for three times. Then, distilled water and $\mathrm{CCl}_{4}$ solution were successively added to break down the red cells of the blood samples. After that, the obtained samples were centrifuged at $4000 \mathrm{rpm}$ for $20 \mathrm{~min}$. The supernatant solution was mixed well with 10 times volume of acetone, and then centrifuged at $3000 \mathrm{rpm}$ for $15 \mathrm{~min}$ to remove the precipitation. The resulting supernatant solution was adjusted to $\mathrm{pH} 7.0$ with $0.1 \mathrm{M} \mathrm{NaOH}$, and diluted 50 times with distilled water. A recovery test was conducted on the samples spiked with hemin at different concentrations $(1.0,2.0$ and $4.0 \mu \mathrm{M})$. The concentration of hemin was analyzed by the above-proposed method.

\section{Results and discussion}

\subsection{Construction of the $\mathrm{Cu}^{2+}$ "turn-on" sensor}

As shown in Scheme 1, the fabrication of the $\mathrm{Cu}^{2+}$ "turn-on" sensor depended on the formation reaction of the water-soluble fluorescent CuNCs. Therefore, we firstly verify whether the fluorescent CuNCs were formed in the presence of $\mathrm{Cu}^{2+}$ by various analytical characterization techniques, such as fluorescence spectra, and UV-vis absorption spectra, TEM and XPS. As can be seen from the inset in Fig. 1A, the as-prepared solution emitted blue fluorescence under irradiation of $365 \mathrm{~nm}$ UV light, which denoted the formation of fluorescent CuNCs. Looking at the three-dimensional fluorescence spectra of the CuNCs, the fluorescence maxima of the CuNCs appeared at 300/380 nm $\left(E_{\mathrm{x}} / E_{\mathrm{m}}\right)$ (Fig. 1A). Moreover, the as-formed CuNCs were stable for at least one month when stored at $4{ }^{\circ} \mathrm{C}$ (Fig. 1B). The TEM image of the CuNCs in Fig. 1C reveals that the average particle size of the CuNCs was $1.5 \pm 0.5 \mathrm{~nm}$, which was well comparable with those reported previously. ${ }^{\mathbf{4 1 , 4 2}}$ The $\mathrm{Cu} 2 \mathrm{p}$ XPS spectrum showed that there were two strong peaks at ca. 953.5 and $933.5 \mathrm{eV}$, which were respectively attributed to the binding energy of $2 \mathrm{p}_{1 / 2}$ and $2 \mathrm{p}_{3 / 2}$ of $\mathrm{Cu}$ or $\mathrm{Cu}^{+}$(Fig. 1D). No satellite peak at ca. $942.0 \mathrm{eV}$ implied the absence of $\mathrm{Cu}^{2+}$ in the CuNCs (Fig. 1D), which was consistent with the previously reported work. ${ }^{43,44}$ This results suggested that during the formation of CuNCs, the $\mathrm{Cu}^{2+}$ precursor was very likely reduced to $\mathrm{Cu}$ or $\mathrm{Cu}^{+}$. The FT-IR spectra of the CuNCs exhibited two strong, protruded and stakeshaped peak at $1400 \mathrm{~cm}^{-1}$ and $1595 \mathrm{~cm}^{-1}$ (Fig. 1E), which were respectively attribute to the symmetric and asymmetric stretching of $\mathrm{COO}^{-}$. In addition, it appeared a powerful and broad band coverage about $3000-3700 \mathrm{~cm}^{-1}$ range, which probably corresponded to the $\mathrm{O}-\mathrm{H}$ stretches. All of the FT-IR results indicated that on the surface of the CuNCs may
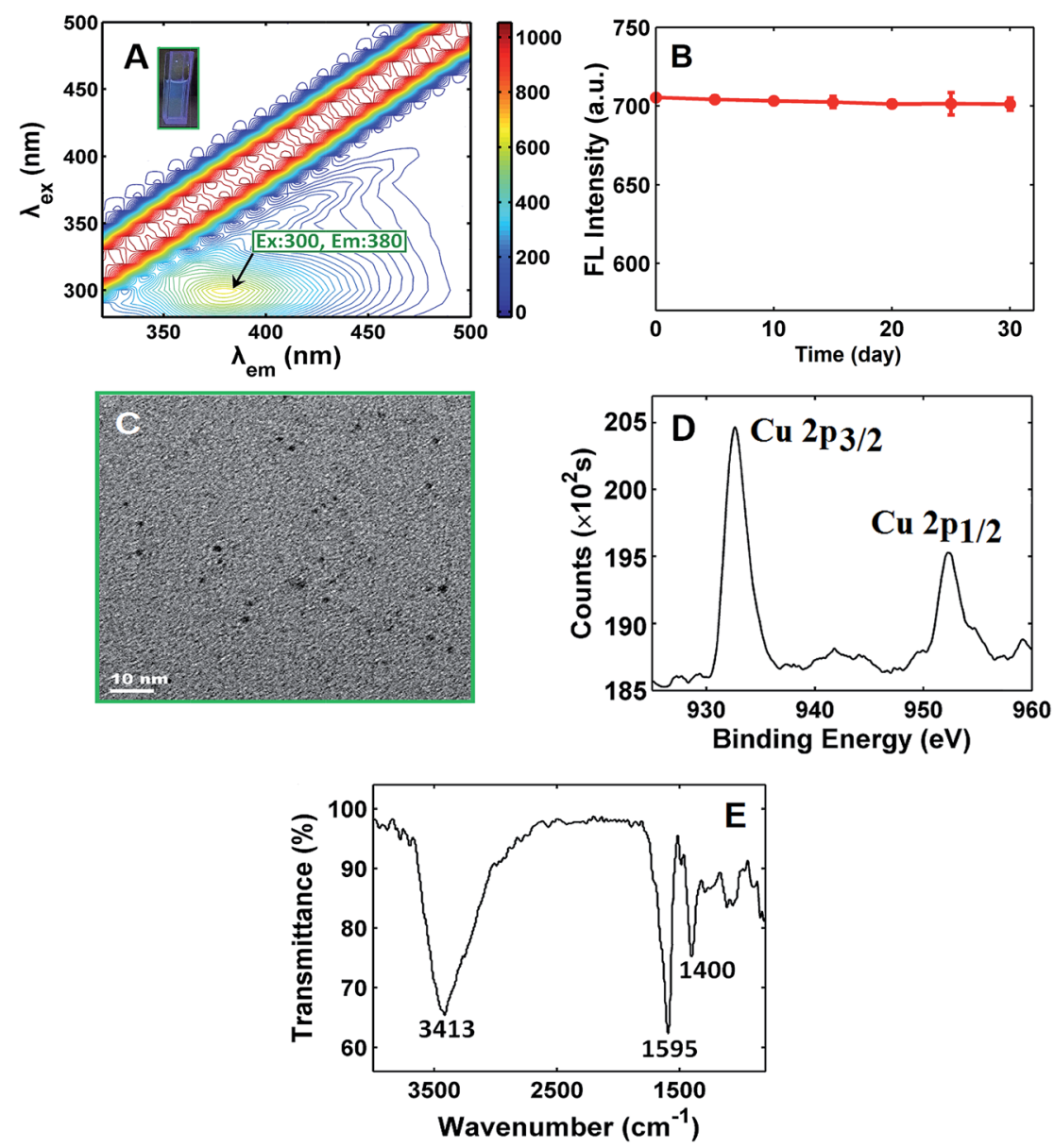

Fig. 1 (A) Three-dimensional fluorescence spectra of the CuNCs. Inset: the related optical photographs. (B) Effect of time on the fluorescence intensity of the CuNCs. (C) TEM image of the CuNCs. (D) High resolution XPS spectra of Cu 2p for CuNCs. (E) FT-IR spectra of CuNCs. 
enclosed $\mathrm{COO}^{-}$and $\mathrm{O}-\mathrm{H}$ functional groups. On the basis of the characterization results, we can suppose that the CuNCs were formed under the aforementioned experimental conditions.

Then, the fluorescence emission spectra were collected in the presence of $\mathrm{Cu}^{2+}$ with different concentrations (Fig. 2A). It was found that the intensity of emission spectral band enhanced as the concentration of $\mathrm{Cu}^{2+}$ increased. There was a good linear relationship between the net fluorescence intensity $\left(F-F_{0}\right)$ and the concentration of $\mathrm{Cu}^{2+}$ ions in the range from 0.05 to $2.0 \mu \mathrm{M}$ with correlation coefficient $(r)$ of 0.998 (Fig. 2A). The limit of detection (LOD) for the $\mathrm{Cu}^{2+}$ sensor was estimated to be $0.032 \mu \mathrm{M}$, which was much less than the maximum contaminant level $(20 \mu \mathrm{M})$ of $\mathrm{Cu}^{2+}$ ions regulated by the US Environmental Protection Agency for safe drinking water. $^{45}$ In addition, compared with those previously reported methods about NMNCs-based fluorescence for $\mathrm{Cu}^{2+}$ detection, the comparable or better results were achieved with respect to linear range and LOD (see Table 1$) \cdot{ }^{31-40}$ To test the selectivity of the sensor toward $\mathrm{Cu}^{2+}$, some environmentally relevant metal ions $\mathrm{Ni}^{2+}, \mathrm{Mg}^{2+}, \mathrm{Ag}^{+}, \mathrm{Co}^{2+}, \mathrm{Cd}^{2+}, \mathrm{Ba}^{2+}, \mathrm{Mn}^{2+}, \mathrm{Ca}^{2+}, \mathrm{Au}^{3+}, \mathrm{Cr}^{3+}$, $\mathrm{Hg}^{2+}, \mathrm{Pb}^{2+}, \mathrm{Al}^{3+}, \mathrm{Fe}^{2+}, \mathrm{Fe}^{3+}, \mathrm{Sn}^{2+}, \mathrm{Ce}^{4+}$ and $\mathrm{Li}^{+}$) were investigated. As shown in Fig. 2B, except for $\mathrm{Cu}^{2+}$, almost no increase in the net fluorescence intensity $\left(F-F_{0}\right)$ with or without other metal ion could be noticed, suggesting the high selectivity of the CuNCs-based sensor toward $\mathrm{Cu}^{2+}$.

\subsection{Construction of the hemin "turn-off" sensor}

The fluorescence emission spectra of CuNCs with different concentrations of hemin were exhibited in Fig. 3A. It could be found from Fig. 3A that the fluorescence intensity was gradually decreased with the increasing concentration of hemin (Fig. 3A). There was a good linear relationship between the net fluorescence intensity $\left(F_{0}-F\right)$ and the concentration of hemin over the
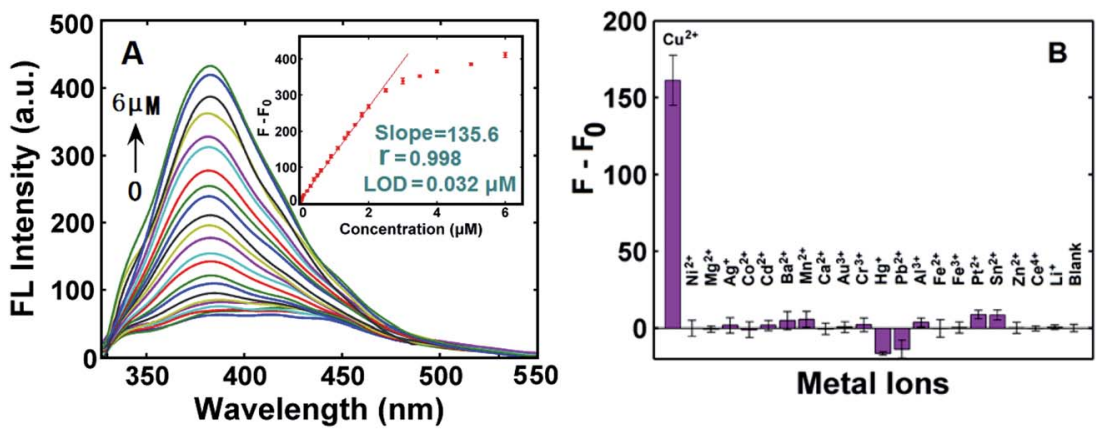

Fig. 2 (A) The emission spectra of CuNCs under $300 \mathrm{~nm}$ excitation with the increasing concentration of the $\mathrm{Cu}^{2+}$. Inset: the calibration plot of $(F$ $-F_{0}$ ) versus $\mathrm{Cu}^{2+}$ concentration, where $F$ and $F_{0}$ respectively represented the fluorescence intensity with and without $\mathrm{Cu}^{2+}$. (B) Selectivity of the "turn on" sensor for $\mathrm{Cu}^{2+}$. The concentration of each metal ion were $1.0 \mu \mathrm{M}$. The error bars are the standard deviation of three measurements.

Table 1 Fluorescence analysis of $\mathrm{Cu}^{2+}$ and hemin: a comparison of the proposed approach with other reported methods

\begin{tabular}{|c|c|c|c|c|}
\hline Probe & Mechanism & Linear range $(\mu \mathrm{M})$ & $\mathrm{LOD}(\mu \mathrm{M})$ & Ref. \\
\hline \multicolumn{5}{|l|}{ Analysis of $\mathrm{Cu}^{2+}$} \\
\hline BSA-capped AuNCs & Electrostatic \& ion-exchanging & $30-500$ & 0.5 & 30 \\
\hline BSA-capped AuNCs & Precipitation & $5-500$ & 5.0 & 32 \\
\hline BSA-capped CuNCs & Intersystem crossing & $0.02-34$ & 0.001 & 33 \\
\hline DNA-capped $\mathrm{Cu} / \mathrm{Ag}$ NCs/MPA ${ }^{a}$ & Oxidation & $0.005-0.2$ & 0.0027 & 34 \\
\hline Sn(II)-citrate-capped AuNCs & Coordination & $0.5-70$ & 0.38 & 38 \\
\hline DTT-capped AuNCs ${ }^{d}$ & Coordination & $0-60$ & 0.08 & 39 \\
\hline Penicillamine-capped CuNCs & Formation-induced FL & $14.8-99.2$ & 4.69 & 40 \\
\hline Cytidine-stabilized CuNCs & Formation-induced FL & $0.05-2.0$ & 0.032 & This work \\
\hline \multicolumn{5}{|l|}{ Analysis of hemin } \\
\hline
\end{tabular}

${ }^{a}$ DNA-capped $\mathrm{Cu} / \mathrm{Ag}$ nanoclusters in the presence of 3-mercaptopropionic acid. ${ }^{b}$ Polyethyleneimine-capped AgNCs. ${ }^{c}$ poly(methacrylic acid)capped AgNCs. ${ }^{d}$ Dithiothreitol-capped AuNCs. ${ }^{e}$ Heparin-mercaptopropionic acid dual modified CdS quantum dots in the presence of protamine. ${ }^{f}$ DNA-reduced graphene oxide in the presence of acridine orange. 

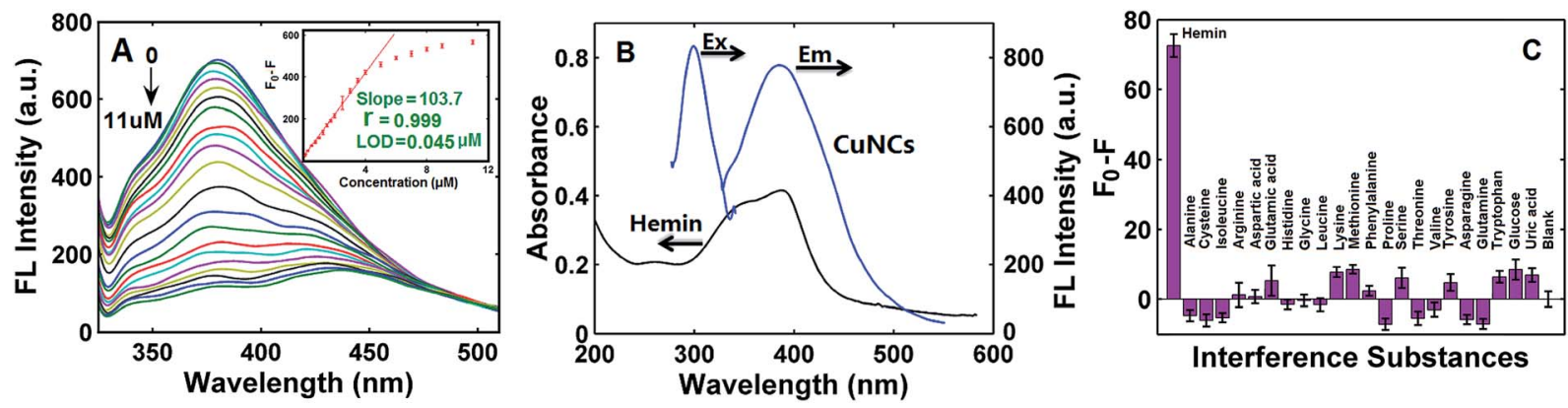

Fig. 3 (A) The emission spectra of CuNCs under $300 \mathrm{~nm}$ excitation with the increasing concentration of the hemin. Inset: the calibration plot of $\left(F_{0}-F\right)$ versus hemin concentration, where $F$ and $F_{0}$ respectively represented the fluorescence intensity of CuNCs with and without hemin. (B) Fluorescence excitation and emission spectra of the CuNCs, and UV-vis absorption spectrum of hemin. (C) Selectivity of the "turn off" sensor for hemin. The concentration of hemin and other substance are $1.0 \mu \mathrm{M}$. The error bars are the standard deviation of three measurements.

0.05-4.0 $\mu \mathrm{M}$ with correlation coefficient $(r)$ of 0.999 (Fig. 3A). The LOD for the hemin sensor was estimated as $0.045 \mu \mathrm{M}$, which was well comparable with those given by other fluorescence-based analysis (see Table 1). ${ }^{21-23}$ Moreover, as in Fig. 3B, the excitation spectrum of the CuNCs had a band peaked at $300 \mathrm{~nm}$, and the emission band of the CuNCs under the excitation of $300 \mathrm{~nm}$ was centered at $380 \mathrm{~nm}$; however, hemin respectively displayed broad absorption at 387,361 , and $260 \mathrm{~nm}$, showing a severe spectral overlap between the absorption band of hemin and the excitation and emission bands of the CuNCs. All spectral overlapping implied that hemin-induced fluorescence quenching of the CuNCs was very possibly caused by the inner filter effect (IFE) of hemin on the fluorescence of the CuNCs. ${ }^{46}$

To test the selectivity of the "turn-off" sensor toward hemin, some possible substances, such as amino acids (alanine, cysteine, isoleucine, arginine, aspartic acid, glutamic acid, histidine, glycine, leucine, lysine, methionine, phenylalanine, proline, serine, threonine, valine, tyrosine, asparagine, glutamine and tryptophan), glucose and uric acid were studied. It was found from Fig. 3C that each substance had a slight or

Table 2 Determination of $\mathrm{Cu}^{2+}$ in lake water samples $(n=3)$

\begin{tabular}{lllll}
\hline Samples & $\begin{array}{l}\text { Added } \\
(\mu \mathrm{M})\end{array}$ & $\begin{array}{l}\text { Mean found } \\
(\mu \mathrm{M})\end{array}$ & $\begin{array}{l}\text { Mean recovery } \\
(\%)\end{array}$ & $\begin{array}{l}\text { RSD } \\
(\%)\end{array}$ \\
\hline 1 & 0 & 0.06 & - & 4.6 \\
2 & 1.00 & 1.02 & 96 & 5.7 \\
3 & 1.50 & 1.56 & 100 & 1.3 \\
4 & 2.00 & 1.93 & 94 & 1.7
\end{tabular}

Table 3 Determination of hemin in duck blood samples $(n=3)$

\begin{tabular}{lllll}
\hline Samples & $\begin{array}{l}\text { Added } \\
(\mu \mathrm{M})\end{array}$ & $\begin{array}{l}\text { Mean found } \\
(\mu \mathrm{M})\end{array}$ & $\begin{array}{l}\text { Mean recovery } \\
(\%)\end{array}$ & $\begin{array}{l}\text { RSD } \\
(\%)\end{array}$ \\
\hline 1 & 0 & 0.09 & - & 6.6 \\
2 & 1.00 & 1.01 & 92 & 6.8 \\
3 & 2.00 & 1.98 & 95 & 4.0 \\
4 & 4.00 & 4.25 & 104 & 1.7
\end{tabular}

negligible effect on the net fluorescence intensity $\left(F_{0}-F\right)$ compared with that of hemin, denoting that the "turn-off" fluorescence sensor had a high selectivity toward hemin.

\subsection{Analysis of $\mathrm{Cu}^{2+}$ and hemin in real samples}

Following the experimental procedures described in Sections 2.4 and 2.5, the proposed sensor was respectively applied to detect $\mathrm{Cu}^{2+}$ in lake water samples and hemin in duck blood samples. The analytical results for $\mathrm{Cu}^{2+}$ detection in lake water samples using the developed method were listed in Table 2, and it was found that the concentration of $\mathrm{Cu}^{2+}$ in lake water was estimated as $0.06 \mu \mathrm{M}$, and the added amount of $\mathrm{Cu}^{2+}$ agreed well with those of found values. The average recovery of $\mathrm{Cu}^{2+}$ reached to $94-100 \%$ with a relative standard deviation (RSD) of 1.3-5.7\%, denoting a good analytical performance of the "turn on" sensor for $\mathrm{Cu}^{2+}$ detection in water sample. The analytical results for hemin detection in duck blood samples were summarized in Table 3. It was found that there existed $0.09 \mu \mathrm{M}$ hemin in the sample, the recoveries varied from $92 \%$ to $104 \%$, and the RSD value was $1.7-6.8 \%$. All these results suggested that the proposed sensing method had potential applications for hemin determination in real samples.

\section{Conclusions}

In summary, we developed a fluorescence "on-off" strategy to detect the $\mathrm{Cu}^{2+}$ and hemin with high sensitivity and good selectivity. The $\mathrm{Cu}^{2+}$ "turn-on" sensing system utilized the formation of fluorescent CuNCs, while the hemin "turn off" sensing system exploited the inner filter effect of hemin on the fluorescence of the CuNCs. The LODs for $\mathrm{Cu}^{2+}$ and hemin were $0.032 \mu \mathrm{M}$ and $0.045 \mu \mathrm{M}$, respectively. It is anticipated that the proposed fluorescence sensing strategy with high sensitivity, low cost and easy to operate can be used for detection of $\mathrm{Cu}^{2+}$ and hemin in some real samples.

\section{Conflicts of interest}

There are no conflicts to declare. 


\section{Acknowledgements}

This research work was financially supported by the National Natural Science Foundation of China (NSFC-21305061), the Natural Science Foundation of Jiangxi Province (20171BAB203018 and 20151BAB203021), the Jiangxi Provincial Department of Education (GJJ160006 and GJJ160204), the State Key Laboratory of Chemo/Biosensing and Chemometrics of Hunan University (SKLCBC-2013010), the State Key Laboratory of Electroanalytical Chemistry (SKLEAC201802), and the Graduate Student Innovation Program of Nanchang University (cx2016053).

\section{References}

1 D. Y. Sasaki, D. R. Shnek, D. W. Pack and F. H. Arnold, Angew. Chem., Int. Ed. Engl., 1995, 34, 905-907.

2 K. C. Ko, J. S. Wu, H. J. Kim, P. S. Kwon, J. W. Kim, R. A. Bartsch, J. Y. Lee and J. S. Kim, Chem. Commun., 2011, 47, 3165-3167.

3 X. Cao, W. Y. Lin and W. Wei, Chem. Commun., 2012, 48, 6247-6249.

4 D. W. Domaille, L. Zeng and C. J. Chang, J. Am. Chem. Soc., 2010, 132, 1194-1195.

5 J. K. Pal and M. Joshi-Purandare, J. Biomed. Sci., 2001, 26, 225-231.

6 T. T. Renjis and T. Pradeep, Langmuir, 2005, 21, 1189611902.

7 M. E. Conrad, B. I. Benjamin, H. L. Williams and A. L. Foy, Gastroenterology, 1967, 53, 5-10.

8 H. D. Maere, M. Jaros, M. Dziewiecka, E. D. Mey, I. Fraeye, M. Sajewicz, H. Paelinck and T. Kowalska, J. Liq. Chromatogr. Relat. Technol., 2014, 37, 2971-2979.

9 S. Dadfarnia, F. Shakerian and A. M. H. Shabani, Talanta, 2013, 106, 150-154.

10 G. P. C. Rao, K. Seshaiah, Y. K. Rao and M. C. Wang, J. Agric. Food Chem., 2006, 54, 2868-2871.

11 L. C. Meng, Z. Y. Fang, J. Lin, M. X. Li and Z. W. Zhu, Talanta, 2014, 121, 205-209.

12 X. L. Chai, X. G. Zhou, A. W. Zhu, L. M. Zhang, Y. Qin, G. Y. Shi and Y. Tian, Angew. Chem., Int. Ed., 2013, 52, 8129-8133.

13 T. Li, B. L. Li and S. J. Dong, Anal. Bioanal. Chem., 2007, 389, 887-893.

14 L. Gao, Y. H. Xiao, Y. P. Wang, X. Chen, B. Zhou and X. Yang, Talanta, 2015, 132, 215-221.

15 T. Hirayama, G. C. V. D. Bittner, L. W. Gray, S. Lutsenko and C. J. Chang, Proc. Natl. Acad. Sci. U. S. A., 2012, 109, 22282233.

16 M. Isaac, S. A. Denisov, A. Roux, D. Imbert, G. Jonusauskas, N. D. McClenaghan and O. Seneque, Angew. Chem., Int. Ed., 2015, 54, 11453-11456.

17 A. W. Zhu, Q. Qu, X. L. Shao, B. Kong and Y. Tian, Angew. Chem., Int. Ed., 2012, 51, 7185-7189.

18 Q. Q. Xu, Z. Q. Li and H. R. Li, Chem.-Eur. J., 2016, 22, 30373043.
19 Z. P. Li, Y. W. Zhang, H. Xia, Y. Mu and X. M. Liu, Chem. Commun., 2016, 52, 6613-6616.

20 U. Baruah, N. Gogoi, G. Majumdar and D. Chowdhury, Sci. World J., 2013, 2013, 529159.

21 S. Sarma, N. Gogoi, B. Sarma and N. Sen, RSC Adv., 2013, 3, 7747-7750.

22 G. M. Guan, J. C. Sha and D. D. Zhu, Microchem. J., 2017, 133, 391-397.

23 Y. Shi, W. T. Huang, H. Q. Luo and N. B. Li, Chem. Commun., 2011, 47, 4676-4678.

24 J. Zheng, P. R. Nicovich and R. M. Dickson, Annu. Rev. Phys. Chem., 2007, 58, 409-431.

25 A. Mathew and T. Pradeep, Part. Part. Syst. Charact., 2014, 31, 1017-1053.

26 E. Gwinn, D. Schultz, S. M. Copp and S. Swasey, Nanomaterials, 2015, 5, 180-207.

27 S. J. Guo and E. K. Wang, Nano Today, 2011, 6, 240-264.

28 X. Yuan, Z. T. Luo, Y. Yu, Q. F. Yao and J. P. Xie, Chem.-Asian J., 2013, 8, 858-871.

29 J. Sun and Y. D. Jin, J. Mater. Chem., 2014, 2, 8000-8011.

30 P. C. Chen, A. P. Periasamy and S. G. Harroun, Coord. Chem. Rev., 2015, 320-321, 129-138.

31 Z. J. Lin, F. Q. Luo, T. Q. Dong, L. Y. Zheng, Y. X. Wang, Y. W. Chi and G. N. Chen, Analyst, 2012, 137, 2394-2399.

32 D. Y. Cao, J. Fan, J. R. Qiu, Y. F. Tu and J. L. Yan, Biosens. Bioelectron., 2013, 42, 47-50.

33 X. Fang, Q. Q. Zhao, H. M. Cao, J. Liu, M. Guan and J. L. Kong, Analyst, 2015, 140, 7823-7826.

34 Y. P. Zhong, J. J. Zhu, Q. P. Wang and Y. He, Microchim. Acta, 2015, 182, 909-915.

35 Y. T. Su, G. Y. Lan, W. Y. Chen and H. T. Chang, Anal. Chem., 2010, 82, 8566-8572.

36 Z. Q. Yuan, N. Cai, Y. Du, Y. He and E. S. Yeung, Anal. Chem., 2014, 86, 419-426.

37 J. Liu, X. L. Ren, X. W. Meng, Z. Fang and F. Q. Tang, Nanoscale, 2013, 5, 10022-10028.

38 S. Chen, Y. F. Kuang, P. P. Zhang, Y. Z. Huang, A. L. Wen, X. Y. Zeng, R. H. Feng, H. D. Nie, X. C. Jiang and Y. F. Long, Sens. Actuators, B, 2017, 253, 283-291.

39 H. Ding, C. S. Liang, K. B. Sun, H. Wang, J. K. Hiltunen, Z. J. Chen and J. C. Shen, Biosens. Bioelectron., 2014, 59, 216-220.

40 D. Li, B. Li and S. I. Yang, Anal. Methods, 2015, 7, 2278-2282. 41 Z. N. Wu, J. L. Liu, Y. Gao, H. W. Liu, T. T. Li, H. Y. Zou, Z. G. Wang, K. Zhang, Y. Wang, H. Zhang and B. Yang, J. Am. Chem. Soc., 2015, 137, 12906-12913.

42 M. Q. Zhao, L. Sun and R. M. Crooks, J. Am. Chem. Soc., 1998, 120, 4877-4878.

43 F. Z. Xu, H. Shi, X. X. He, K. M. Wang, D. G. He, Q. P. Guo, Z. H. Qing, L. Yan, X. S. Ye, D. Li and J. L. Tang, Anal. Chem., 2014, 86, 6976-6982.

44 X. F. Jia, J. Li and E. R. Wang, Small, 2013, 9, 3873-3879.

45 Y. Wang, F. Yang and X. R. Yang, Nanotechnology, 2010, 21, 3293-3294.

46 J. R. Lakowicz, Principles of Fluorescence Spectroscopy, Springer, New York, 3rd edn, 2006. 